Goldschmidt 2021 Abstract

https://doi.org/10.7185/gold2021.5453

\section{Developing apatite as an indicator mineral for exploration: insights from layered intrusions}

\author{
MARIE A. KIEFFER ${ }^{1}$ AND SARAH A. S. DARE ${ }^{2}$ \\ ${ }^{1}$ University of Quebec in Chicoutimi \\ ${ }^{2}$ Universite du Quebec a Chicoutimi (UQAC) \\ Presenting Author: marie.kieffer1@uqac.ca
}

Apatite is a weathering-resistant mineral that occurs in most igneous, sedimentary, metamorphic and hydrothermal rocks. Trace element chemistry in apatite is typically used for tracking magmatic processes [1] and as a provenance indicator for sedimentary studies [2]. Other studies also show the potential of apatite as an indicator mineral for mineral exploration [3, 4]. However, these studies mainly focus on felsic rocks and hydrothermal deposits. Apatite from mafic layered intrusions which are important hosts of Fe-Ti-V-P resources - have not been included in previous discrimination diagrams. Additionally, several processes may influence the trace element composition of apatite during and/or after its crystallisation (e.g., subsolidus reequilibration). It is not yet known if their influence on apatite chemistry is significant, nor if they could hinder or help the use of apatite as an indicator mineral for exploration purposes. This study uses a petrogenetic approach to improve our understanding of apatite chemistry from layered intrusions, thus enlarging its use as a provenance indicator. Microprobe (Laval University) and LA-ICP-MS analyses (LabMaTer, UQAC) are used to obtain, respectively, the volatile content and full suite of trace elements of apatites from mafic layered intrusions (e.g. Sept-Iles, Quebec; Bushveld, South Africa), as well as granites (Sept-Iles granites, as the most differentiated part of the intrusion, and others). These new data are also compared to a compilation of apatites from other mafic and felsic rocks. Our results show that apatite from mafic layered intrusions display a distinct signature from apatite in felsic rocks (e.g. lower REE, $\mathrm{V}$ or $\mathrm{Mg}$, and higher Th, U or As), as a result of protracted fractional crystallisation (Fig. 1). Apatites from the mineralised (oxide-apatite) parts of layered intrusions are chemically different (e.g. more $\mathrm{Mn}$ ) to apatite from unmineralised mafic parts. In addition, elements such as $\mathrm{U}, \mathrm{Th}$ or $\mathrm{Pb}$ in apatite can reflect crustal contamination of the host intrusions.

[1] Tollari et al. (2008), Chemical Geology 252 (3-4), 180190. [2] O'Sullivan et al. (2020), Earth-Science Reviews 201, 103044. [3] Belousova et al. (2002), Journal of Geochemical Exploration 76, 45-69. [4] Mao et al. (2016), Economic Geology 111 (5), 1187-1222.

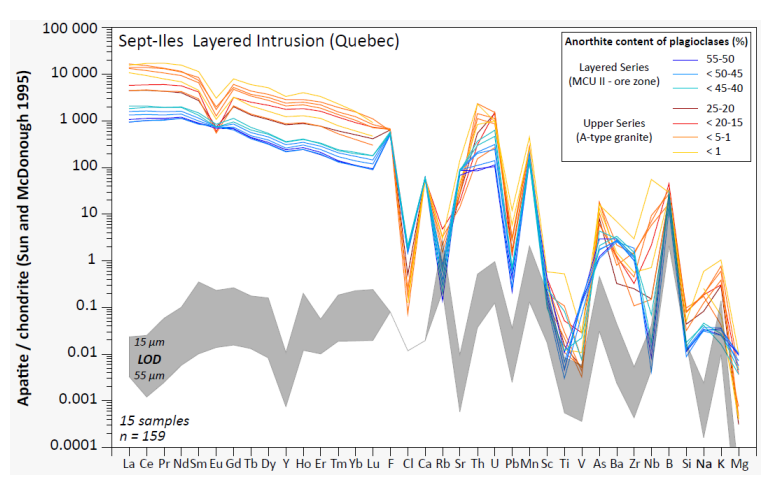

